\title{
Migration and Reallocation of Educational Resources in China - From the Perspective of Educational Resource Capacity
}

\author{
Jing Liu ${ }^{1}$, Yongchong $\mathrm{Mao}^{2} \&$ Jinhua Zhang ${ }^{1}$ \\ ${ }^{1}$ Research Institute of Finance and Economics, Shanghai University of Finance and Economics, Shanghai, China \\ ${ }^{2}$ Ernst \& Young U.S. LLP. \\ Correspondence: Dr. Jinhua Zhang, Research Institute of Finance and Economics, Shanghai University of \\ Finance and Economics, 777 Guoding Road, Shanghai 200433, China. Tel: 86-21-6591-6512. E-mail: \\ zhang.jinhua@mail.shufe.edu.cn
}

Received: December 23, 2016

Accepted: January 6, 2017

Online Published: February 3, 2017

doi:10.20849/aes.v2i1.109

URL: http://dx.doi.org/10.20849/aes.v2i1.109

\begin{abstract}
The massive rural-to-urban migration, which tends to occur more frequently in family units, has caused increasing children to follow their migrant parents to cities. The surges of migrant children relocating to cities trigger a strong demand for compulsory education for migrant children in migrant inflow cities and raise challenges for capacity of urban educational resources. This study discovers that China suffers from a severely unequal distribution of educational resources across different regions as well as a significant imbalance between supply and demand of education. The allocation of educational resources is subject to the capacity of education supply. Based on a review of the population distribution and the trend of recent migration in China, an analysis is conducted to simulate migrant children's migration behavior. The analysis results imply that the flow of the demand for education caused by the migrant children benefits the maintenance of an equitable education system. It is recommended that regional supplemental education solutions be identified in migrant outflow regions. It is encouraged that migrant outflow regions make more effort to accommodate migrant children. More specifically, it is encouraged to make more flexible and customized distribution of educational resources so that an allocation mechanism suitable for the massive rural-to-urban migration can be established.
\end{abstract}

Keywords: migration, migrant children, reallocation of educational resources, capacity, China

\section{Introduction}

As China experiences rapid economic growth and urbanization, a massive population shifts from rural and small city areas towards urban and big city areas. With the reform of the household registration (i.e., Hukou) system lagged far behind, these migrants are unable to become new legal immigrants of the cities. Instead, they become part of the vast floating population (i.e., temporary migrants with unregistered household status) of the cities. In recent years, with the growth of the floating population in China, the population of migrant children increases substantially. In 2013, China had a floating population of 245 million, accounting for 18.01 percent of the total population. Among the temporary migrants, 62.5 percent of the migrant children aged 6 to 15 follow their parents to the cities. (Annual Report of the Development of Migrant Population in China, 2014)

Large-scale children's migration towards the cities results in a strong demand for compulsory education in the cities. To ensure that children of temporary migrants receive equal education opportunities as local children and that they participate in high-quality education programs, the Ministry of Education decreed that "local government for migrant settlement plays a major role in migrant children's education" and that "it is a major responsibility for the local public school to accommodate school-age migrant children based on relevant rules." Moreover, the Ministry of Education promised to "include migrant children in the development plan for regional education and include educational funds for migrant children in its financial coverage." (i.e., Policy of Double Majors and Double Inclusions) In response, local governments started to adjust their respective policies for admission and gradually reduced the barriers to enrollment for migrant children. However, driven by the planned economy for a long time, the current system of education finance relies heavily on local / county-level authorities and some limited adjustment cannot keep in pace with the massive increase of migrant children. Hoping that their children can receive higher quality education, it is typical for migrants to compete to enroll their children to a better region, a better school, and / or a better class. The education market becomes a very 
tight market due to the imbalance of supply and demand for educational resources (Tooley et al., 2011).

From an education system perspective, school-age children's migration serves as a facilitator for education development across different regions. It improves integrity of the development of national education and provides a more efficient solution for allocation of educational resources (Xiang, 1998). Outline of china's national plan for medium and long-term education reform and development $(2010-2020)$ also states that it will be a focus in the next stage to efficiently allocate educational resources and achieve harmony and sustainability in the education system. It is recommended for allocation of educational resources to focus not only on short-term benefits but also on medium and long-term comprehensive social development. Migration and relocation lead to changes in allocation of educational resources. In response to the changes, it is necessary to make adjustments to the current allocation of educational resources. It is encouraged to accumulate and integrate human capital required by social development, which improves the overall level of education in the society and provides substantial support for the second demographic dividend in China (Wang and Mason, 2005; Cai, 2010). Therefore, it is important to develop educational resource allocation standards that take into account the massive migration in China based on an analysis of migration trends.

\section{Migration and Allocation of Educational Resources}

With the continuous growth of migrant population, it becomes typical for children to follow their migrant parents to cities to live and study. The Ministry of Education includes migrant children in its development plan for compulsory education in the hopes that migrant children can receive equal education opportunities as local children and that they can participate in high-quality education programs. However, it is still difficult for the current settings and allocation to make immediate adjustments based on the expanded needs for education. The admission for migrant children is still challenging. The allocation of educational resources is obviously problematic and the conflicts arisen from this lead to widespread and sustained attention from media and academia (Liang and Chen, 2007).

\subsection{Demand for Education Driven by Migration}

\subsubsection{Patterns of Migration}

As indicated in existing researches and micro-survey results, migrants in China follow the following two patterns. First, the scale of migrants is increasingly expanding with geographical concentrations. Since 1980s, migrant population in China grew at a rapid rate. The origin and settlement regions went through a process of geographical concentration (Duan and Yang, 2009). Migrants tend to follow capital and migrate to primarily economically developed regions. Secondly, family-oriented migrations become common - migrants usually bring their children and parents with them (Duan et al., 2013). While migrant population continues to expand, the structure of migrants and the patterns of migration start to change. The majority of the migrants evolve from those who engage in hard labor just to make a living to those who come to build and enjoy a new family life with the hope that their children can receive good education.

\subsubsection{Demand for Education Driven by Migration}

In 2013, school-age migrant children totaled 12.77 million, 4.33 million of which were elementary school children. Children left behind in their origins by their migrant parents totaled 21.27 million, 14.40 million of which were elementary school children (Source: 2013 Statistics Bulletin Boards for National Educational Development in China). While educational resources are scarce in the tight education market, high-quality education resources are even scarcer. To obtain access to better educational resources, most migrants end up relocating their children left behind earlier to their settlements. Migrants' geographical concentration leads to geographical concentration of migrant children and children left behind in respective regions. Migrant children are observed to be mainly in Guangdong, Zhejiang, Shanghai, Beijing, Jiangsu while children left behind are mainly in Henan, Sichuan, Anhui, Hunan, Jiangxi and other regions. Moreover, migration in China is in the process of transitioning from stage two to stage three of the demographic transition model. Existing research indicates that family migration pattern increases the probability of children's following their migrant parents to the cities. Therefore, it is expected that more children left behind by their parents earlier will follow their migrant parents to the cities at this stage, resulting a larger population of migrant children in different regions. An enlarged school-age population certainly puts additional pressure to the existing educational resources. Further studies are needed to determine whether cities have sufficient educational resources, room, and capacity. 

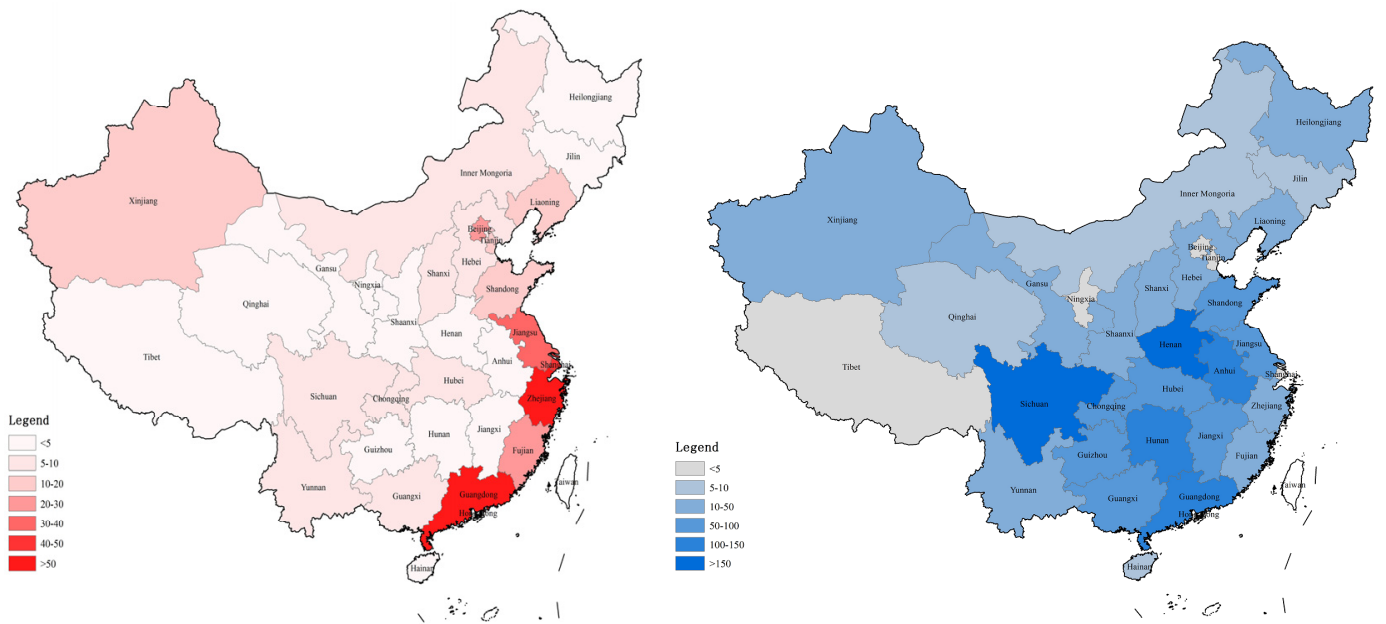

Figure 1. Distribution of elementary school age (6 to 11) migrant children and children left behind

Source: 2014 Statistics of Migrant Children in China, 2013 Research Report of Rural Left-behind (Unaccompanied) Children and Urban Migrant Children, and 2010 Sixth Population Census Data in China.

\subsection{Analysis of Provincial Educational Resource Capacity}

\subsubsection{Methodology and Summary of Statistics}

Educational resources are the sum of human, material and financial resources used or consumed in the education process. Indicators are created and indices are derived based on previous literature, theoretically and empirically linking them to educational resource capacity. Principles of optimization, conciseness and feasibility are also carefully considered in selection of the indicators. The number of students accommodated by different educational resources as specified by educational standards, referred to as Education Choice and Competition Index (ECCI), can be utilized to reflect capacities of educational resources. The ECCI for an educational resource equals to the ratio of the actual number of students accommodated by the specific resource to the number of students accommodated by different educational resources as specified by educational standards (Wu, 2010). An ECCI greater than one indicates that the type of resource is overused. Similarly, an ECCI less than one indicates that there's capacity for the type of resource. An ECCI equal to one indicates that the capacity for the type of resource is in the marginal state - just enough to meet the associated educational demand. For example, ECCI for teacher's workload indicates the actual number of students assigned to each teacher as it compares to the standard student-teacher ratio. Mathematically, ECCI for Teacher's Workload = Actual Student-Teacher Ratio / Standard Actual Student-Teacher Ratio. In 2013, there are 792,476 elementary school students and 48,578 elementary school teachers in Shanghai. Moreover, the standard student-teacher ratio for elementary schools in

Shanghai is 19:1. The associated ECCI for teacher's workload in Shanghai $=\frac{792,476 \div 48,578}{19: 1}=0.86$.

The ECCI for teacher's capability measures teacher's education based on the teachers' academic standards set by Ministry of Education: 1 for associate degrees, 1.2 for bachelor's degrees, 1.5 for master's degrees, and -1.2 for high school diploma or equivalents. An ECCI of one for teacher's education indicates that the teacher meets the education requirements of Ministry of Education. A list of these indicators and indices derived is provided in Table 1 below.

The ECCI for school building capacity utilization is the ratio of actual average square meters of school building per student to the required average square meters of school building per student. Mathematically, ECCI for school building capacity utilization $=$ actual school building capacity $/$ required school building capacity $=$ Number of Students at School / (Actual Square Meters of School Building Areas / Required Average Square Meters of School Building Areas per Student). For example, School building areas totaled 5,022,320 square meters in 2013 and it is required that each student needs eight square meters of school building areas. The 
associated ECCI for school building capacity utilization $=792,476 /(5,022,320 / 8)=1.26$. An ECCI greater one indicates that the school buildings in Shanghai is overloaded in 2013.

The ECCI for teaching facility capacity utilization gauges the advanced teaching facilities allocated to each student. Mathematically, the ECCI for teaching facility capacity utilization = (Actual Number of Students at Schools / Actual Number of Computers the Schools have) / Standard Number of Students Accommodated per Computer. In 2013, there are 146,555 computers in elementary schools in Shanghai and it is required that a computer can at most accommodate ten students. Therefore, the ECCI for teaching facility capacity utilization = $(792,476 / 146,555) /(10: 1)=0.54$. An ECCI well below one indicates that elementary schools in Shanghai generally have sufficient advance teaching facilities in 2013.

Table 1. Indicators and indices derived for educational resource capacity

\begin{tabular}{|c|c|c|c|}
\hline Objective & Criterion & Indicator & ECCI \\
\hline \multirow{5}{*}{$\begin{array}{c}\text { Overall } \\
\text { Educationa } \\
1 \text { Resource } \\
\text { Capacity }\end{array}$} & \multirow[t]{2}{*}{ Human Resource Capacity } & $\begin{array}{c}\text { Number of } \\
\text { Full-time Teachers }\end{array}$ & Teacher's Workload \\
\hline & & Teacher's Education & Teacher's Capability \\
\hline & \multirow{2}{*}{ Material Resource Capacity } & $\begin{array}{c}\text { School Building } \\
\text { Area }\end{array}$ & $\begin{array}{c}\text { School Building } \\
\text { Capacity Utilization }\end{array}$ \\
\hline & & $\begin{array}{l}\text { Number of Advanced } \\
\text { Teaching Facilities }\end{array}$ & $\begin{array}{c}\text { Teaching Facility } \\
\text { Capacity Utilization }\end{array}$ \\
\hline & Financial Resource Capacity & $\begin{array}{l}\text { Expenditure on } \\
\text { Education }\end{array}$ & $\begin{array}{c}\text { Education Expenditure } \\
\text { per capita }\end{array}$ \\
\hline
\end{tabular}

Indicators above are mainly selected to evaluate teaching conditions and to reflect teaching quality. Indicators selected to evaluate teaching conditions include Expenditure on Education, Number of Teaching Facilities, and Number of Full-time Teachers. Indicators selected to reflect teaching quality include School Building Area and Teacher's Education. Utilizing the indicators, an analysis was conducted to evaluate the educational resource capacities for the elementary schools in the regions where migrant children concentrate geographically (i.e., Guangdong, Zhejiang, Shanghai, Beijing, and Jiangsu) and where children left behind concentrate geographically (i.e., Henan, Sichuan, Anhui, Hunan, and Jiangxi). The regions where migrant children concentrate and the regions were children left behind concentrate are referred to herein and after as migrant in-flow regions and migrant out-flow regions, respectively. The analyses in this study is based on the data from 2013 China Educational Statistical Yearbook, 2013 China Educational Finance Statistical Yearbook, and 2014 China Statistical Yearbook. In particular, all the standards referenced in this study are from Modern Educational Facilities Standards for Elementary Schools, provincial Reference Standard for Compulsory Education, and provincial Construction Standard for Buildings in Elementary and Secondary Schools.

\subsubsection{Capacity Analysis}

Table 2. Capacities of educational resource for elementary schools

Human Resource Capacity

- ECCI for Teacher's Workload

\begin{tabular}{cccc}
\hline $\begin{array}{c}\text { Migrant } \\
\text { inflow } \\
\text { Region }\end{array}$ & $\begin{array}{c}\text { ECCI for } \\
\text { Teacher's } \\
\text { Workload }\end{array}$ & $\begin{array}{c}\text { Migrant } \\
\text { outflow } \\
\text { Region }\end{array}$ & $\begin{array}{c}\text { ECCI for } \\
\text { Teacher's } \\
\text { Workload }\end{array}$ \\
\hline Guangdong & 1.08 & Henan & 1.16 \\
Shanghai & 0.86 & Sichuan & 1.04 \\
Beijing & 0.77 & Anhui & 1.09 \\
Zhejiang & 1.06 & Hunan & 1.19 \\
Jiangsu & 0.95 & Jiangxi & 1.32 \\
\hline
\end{tabular}

Human Resource Capacity

- ECCI for Teacher's Capability

\begin{tabular}{cccc}
\hline $\begin{array}{c}\text { Migrant } \\
\text { inflow } \\
\text { Region }\end{array}$ & $\begin{array}{c}\text { ECCI for } \\
\text { Teacher's } \\
\text { Capability }\end{array}$ & $\begin{array}{c}\text { Migrant } \\
\text { outflow } \\
\text { Region }\end{array}$ & $\begin{array}{c}\text { ECCI for } \\
\text { Teacher's } \\
\text { Capability }\end{array}$ \\
\hline Guangdong & 0.85 & Henan & 0.76 \\
Shanghai & 1.09 & Sichuan & 0.79 \\
Beijing & 1.13 & Anhui & 0.69 \\
Zhejiang & 1.01 & Hunan & 0.71 \\
Jiangsu & 0.97 & Jiangxi & 0.59 \\
\hline
\end{tabular}


Material Resource Capacity

- ECCI for School Building Capacity Utilization

\begin{tabular}{cccc}
\hline $\begin{array}{c}\text { Migrant } \\
\text { inflow } \\
\text { Region }\end{array}$ & $\begin{array}{c}\text { ECCI for } \\
\text { School } \\
\text { Building } \\
\text { Capacity } \\
\text { Utilization }\end{array}$ & $\begin{array}{c}\text { Migrant } \\
\text { outflow } \\
\text { Region }\end{array}$ & $\begin{array}{c}\text { ECCI for } \\
\text { School } \\
\text { Building } \\
\text { Capacity } \\
\text { Utilization }\end{array}$ \\
\hline Guangdong & 1.05 & Henan & 1.44 \\
Shanghai & 1.26 & Sichuan & 1.37 \\
Beijing & 0.97 & Anhui & 1.33 \\
Zhejiang & 1.07 & Hunan & 1.20 \\
Jiangsu & 1.09 & Jiangxi & 1.43 \\
\hline
\end{tabular}

Material Resource Capacity - ECCI for Teaching Facility Capacity Utilization

\begin{tabular}{cccc}
\hline $\begin{array}{c}\text { Migrant } \\
\text { inflow } \\
\text { Region }\end{array}$ & $\begin{array}{c}\text { ECCI for } \\
\text { Teaching } \\
\text { Facility } \\
\text { Capacity } \\
\text { Utilization }\end{array}$ & $\begin{array}{c}\text { Migrant } \\
\text { outflow } \\
\text { Region }\end{array}$ & $\begin{array}{c}\text { ECCI for } \\
\text { Teaching } \\
\text { Facility } \\
\text { Capacity } \\
\text { Utilization }\end{array}$ \\
\hline Guangdong & 1.08 & Henan & 3.07 \\
Shanghai & 0.54 & Sichuan & 1.72 \\
Beijing & 0.39 & Anhui & 1.62 \\
Zhejiang & 0.64 & Hunan & 2.12 \\
Jiangsu & 0.71 & Jiangxi & 2.85 \\
\hline
\end{tabular}

In general, educational resources are really scarce in China. Regardless of migrant inflow or outflow regions, educational resources are somewhat overused. It is worth mentioning that the relevant standards for allocation of educational resources set by the Ministry of Education in 2001 are still followed today. The required educational resources specified by those outdated standards not only are insufficient to meet the normal educational needs but also fail to ensure that every student can receive decent-quality education. However, raising the standards for educational resources allocated to each school will make the current educational resource shortage worse.

The allocation of educational resources is significantly imbalanced between migrant inflow and outflow regions. First, there is insufficient number of qualified teachers and very limited school building areas in the migrant outflow provinces. In particular, advanced teaching facilities are extremely scarce. There seem to be relatively sufficient educational resources in the migrant inflow provinces. More specifically, there are sufficient number of qualified teachers and advanced teaching facilities. Each province has a teaching facility capacity utilization of $40 \%$ to $70 \%$ except Guangdong. But school building areas are relatively insufficient. Secondly, school building areas are typically overused in the migrant outflow provinces, and in particular in Henan. The ECCI for utilization of school building and teaching facility capacity are 1.44 and 3.07 for Henan, respectively. Moreover, teachers are typically underqualified and overloaded in the migrant outflow provinces, and in particular in Jiangxi. The ECCI for teacher's workload and capability are 1.32 and 0.59 , respectively. Among the migrant inflow regions, the educational infrastructure is historically robust in Beijing, Guangdong, Shanghai, and Zhejiang. Allocation of educational resources in those four regions is relatively more appropriate than the other regions. Nonetheless, Shanghai has insufficient school building resources with an ECCI for school building capacity utilization of 1.27. Zhejiang and Guangdong both have an insufficient number of teachers with an ECCI of 1.08 and 1.06, respectively.

Existing literature indicates that school-age children's migration leads to a reallocation of demand for education. Educational resources are under-utilized and wasted in migrant outflow regions due to inadequate supply of educational resources coupled with the dramatic decrease in school-age children ( $\mathrm{Gu}$ and $\mathrm{Pu}, 2013$ ). Consistent with existing literature, the study finds that migrant inflow regions have more educational resource capacities compared with migrant outflow regions. Inconsistent with existing literature, educational resources are not found to be under-utilized or wasted in migrant outflow regions, as indicated by existing literature. The pressure on educational resources is still high for migrant outflow regions.

\subsubsection{Further Analysis}

There is a big gap between the demand and supply for educational resources to both migrant children and children left behind. The gap is not only determined by the allocation of human and material resources but also determined by the level of economic development and the education expenditure as a percentage of the total expenditure. The different education expenditure made by regions is a major reason why educational resources are imbalanced across different regions (Landau, 1997; Wu, 2008). In general, education expenditure per capita is significantly higher in migrant inflow regions than that in migrant outflow regions. As indicated in Figure 2, the 2013 public budget for education expenditure per capita in Beijing, Shanghai, and Jiangsu exceeds ten thousand RMB. Dramatically, the 2013 education expenditure per capita in Beijing, the highest among all 
regions, is around six times as high as that in Henan, the lowest among all regions. As shown in Figure 3, the significant difference is expected to become even larger among different provinces with respect to their education expenditures going forward.

Considering that regional GDP is positively correlated with financial income and that regional finance is determined by regional economic development, this study uses economic support for education as an indicator to evaluate the potential supply of educational resources across different regions. ECCI for educational expenditure per capita, calculated as the ratio of the sum of budgeted educational expenditure per capita and budgeted public expenditure per capita to GDP per capita, is utilized as a unit of measurement.

The lower the ECCI for educational expenditure per capita is, the less pressure is placed on GDP per capital and the more support educational resources can leverage from GDP per capital. Based on our analysis, ECCI for educational expenditure per capita for Beijing and Shanghai are lower than national average, indicating that those two cities have decent educational resource supply.

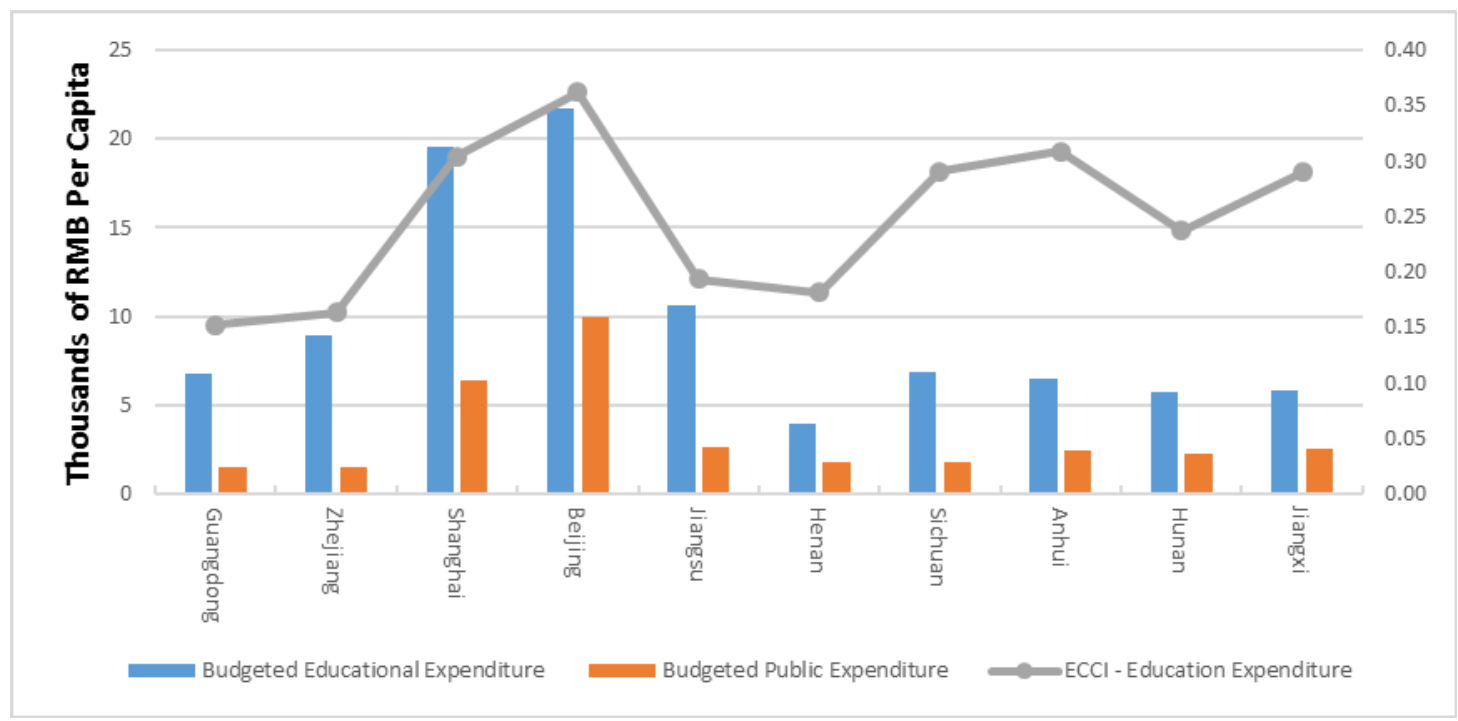

Figure 2. Geographical distribution of education expenditure per capita

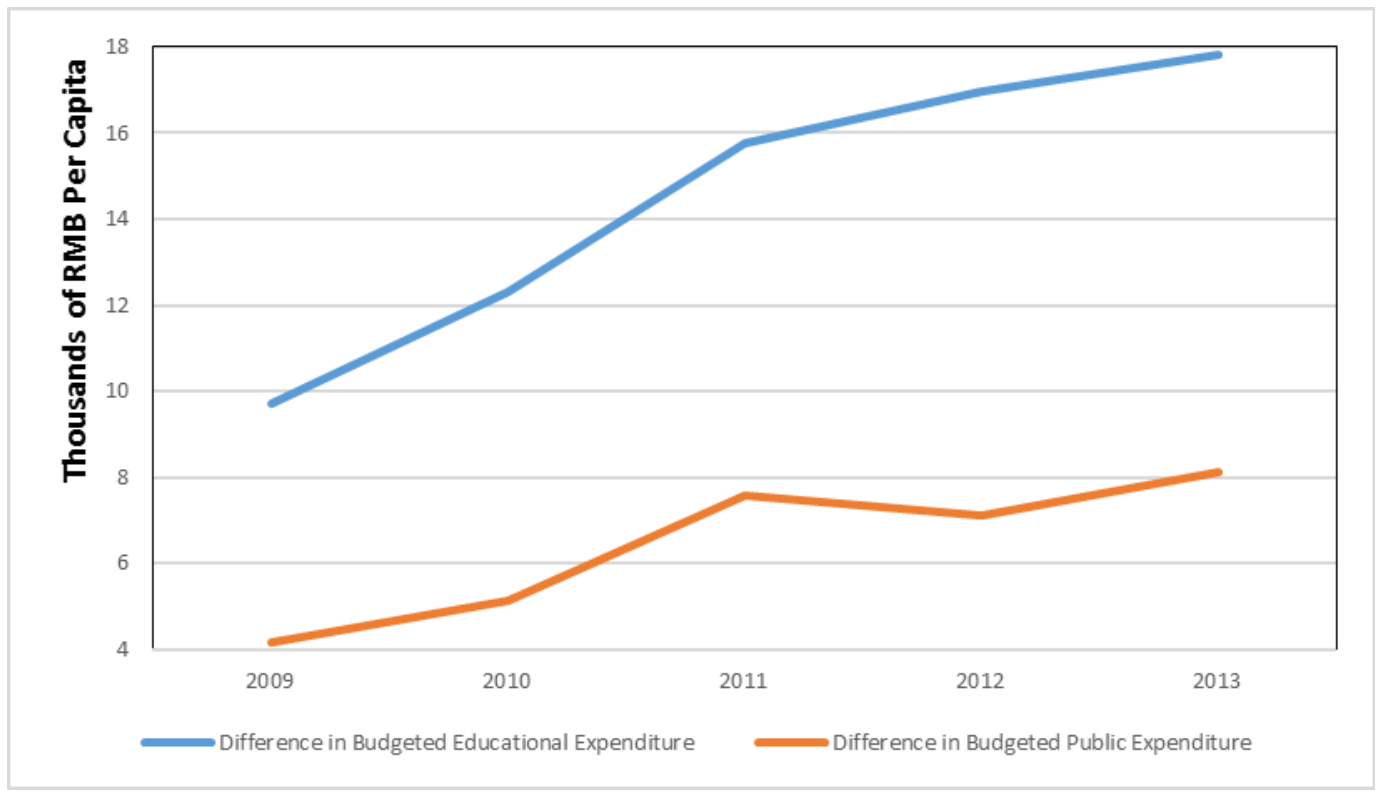

Figure 3. Public budget for educational expenditure per capita - Beijing vs Henan 
The reason behind the severely imbalanced allocation of compulsory educational resources across different regions in China, and the insufficient supply of good quality education in particular, is essentially a problematic education expenditure policy and system. Large numbers of migrant workers create additional social wealth and make large tax contributions to the society. They provide the migrant inflow cities with crucial financial resources for the development of the urban social undertakings. However, as the children follow their migrant parents to the cities, education expenditures, which used to be made by the government of migrant outflow cities, are made by the government of migrant inflow cities instead. It will take some time before the governments of migrant inflow cities can complete fully implementing the education policy of making educational expenditures based on the actual number of migrant children. The education quality for migrant children is somewhat uncertain. It is suspected that education for migrant children becomes discriminatory. The spillover effect of human resources empowers education to break through the realm of regional public goods and become national public goods. It is absolutely unfair for the current policy to enable migrant inflow regions to receive social benefits provided by migrant outflow region without requiring migrant inflow regions to provide associated financial support.

\section{Simulation Analysis of Allocation of Educational Resources}

The flow of demand for education driven by migration is beneficial to evenly distribute educational resources across regions. Contradictorily, the extra "barrier to admission" created by regional governments specifically for migrant children holds up the migrant children from being enrolled into schools on time and prohibits the educational resources from further reallocation. As family-oriented migration progresses coupled with the further implementation of the Policy of Double Majors and Double Inclusions, many children left behind in the countryside will become legal immigrants in the cities. It becomes imperative for allocation of educational resource to conform to the population flows and structural changes. Therefore, a simulation analysis is conducted to simulate the migration process and associated changes in educational resource capacity, based on migration trends and geographical distribution of migrants. The simulation analysis aims to provide evidence for the need to promote equal educational opportunities and to more appropriately allocate educational resources, in the hopes that national education plans can be adjusted accordingly to adjust to the massive migration.

\subsection{Migration Simulation}

Because the decision for the elementary school children left behind to make on whether to make provincial migration or inter-provincial migration is driven by the ratio of provincial migrants to inter-provincial migrants, the number of provincial migrant children and the number of inter-provincial migrant children can be estimated, assuming the $2010-2013$ geographical distribution of migrants across provinces is constant. The number of children for each migrant outflow region expected to migrate to migrant inflow regions can be further estimated based on household registration information contained in the 2010 Sixth Population Census Data in China.

Considering that young migrant children (i.e., children that are younger than six years old) are subject to a set of externalities such as long-term parents' away, lack of parental care, lack of family love, lack of education and supervision, inadequate safety protection, and etc. and that it's difficult to remove those externalities, data for school-age inter-province migrant children (aged 6 to 11) is first selected for the purpose of the analysis.

Based on the above considerations, some resampling techniques (i.e., simulation) are used to estimate the number of children following their parents to migrate inter-provincially and the number of children following their parents to migrate within the province. The rationale behind using resampling techniques is to first estimate the geographical distribution of rural unaccompanied elementary school children for each province, assuming that the number of rural unaccompanied children for a province, as a percentage of the total number of rural unaccompanied children in the country, remains constant. Migrants are grouped into two categories by the 2010 Sixth Population Census Data in China - inter-provincial migrants and provincial migrants. Based on those facts, the percentage of inter-provincial migrants among all migrants can be derived. For example, $28 \%$ of migrants in Beijing and $54 \%$ of migrants in Henan are inter-provincial migrants. Assuming all unaccompanied children will follow their migrant parents to the cities, the percentage of children following their inter-provincial / provincial migrant parents can then be estimated (percentage of children following their inter-provincial migrant parents = percentage of inter-provincial migrants among all migrants). As such, $28 \%$ of unaccompanied children in Beijing and $54 \%$ of unaccompanied children in Henan are expected to follow their inter-provincial migrant parents to the cities. Plugging in the total number of unaccompanied children, the number of unaccompanied children in each province expected to follow their inter-provincial migrant parents to the cities can then be estimated. As shown in Table three below, around four thousand unaccompanied children in Beijing and 830 thousand unaccompanied children in Henan are expected to follow their inter-provincial migrant parents to the cities. 
Table 3. Results of simulation analysis - Outflow

\begin{tabular}{crcrr}
\hline Major Inflow Cities & $\begin{array}{c}\text { Unaccompanied } \\
\text { Children }\end{array}$ & $\begin{array}{c}\text { \% of Inter-provincial } \\
\text { Migrant Children }\end{array}$ & $\begin{array}{c}\text { Expected } \\
\text { Outflow }\end{array}$ & $\begin{array}{c}\text { Expected } \\
\text { Inflow }\end{array}$ \\
\hline Guangdong & $1,034,259$ & $6 \%$ & 66,469 & $1,751,013$ \\
Shanghai & 18,726 & $28 \%$ & 5,281 & 613,054 \\
Beijing & 14,405 & $28 \%$ & 3,993 & 404,698 \\
Zhejiang & 275,130 & $21 \%$ & 58,978 & 943,866 \\
Jiangsu & 700,070 & $27 \%$ & 188,740 & 529,462 \\
\hline \hline Major Outflow Cities & & & & \\
Henan & $1,545,627$ & $54 \%$ & $\mathbf{8 2 9 , 5 7 0}$ & 34,179 \\
Sichuan & $1,633,496$ & $49 \%$ & 800,847 & 81,297 \\
Anhui & $1,045,783$ & $66 \%$ & 690,394 & 46,922 \\
Hunan & $1,027,057$ & $54 \%$ & 555,525 & 49,896 \\
Jiangxi & 877,248 & $60 \%$ & 525,686 & 38,719 \\
Total & $\mathbf{6 , 1 2 9 , 2 1 1}$ & & & \\
\hline
\end{tabular}

\subsubsection{Outflow}

Among the children that have inter-provincial migrant parents, it is estimated that most of them will leave from one of the five major migrant outflow regions including Henan, Sichuan, Anhui, Hunan, and Jiangxi. As expected, based on the results of the simulation analysis, such children total 830 thousand in Henan, 800 thousand in Sichuan, 690 thousand in Anhui, 556 thousand in Hunan, and 526 thousand in Jiangxi. Summing up all the unaccompanied children in each province expected to follow their inter-provincial migrant parents to the cities, one can see that around 613 thousand unaccompanied children are expected to follow their inter-provincial migrant parents to the cities among 1.44 million migrant children in China. (Where do those two numbers come from?)

\subsubsection{Inflow}

Taking into account the geographical distribution of migrant population in different regions, the geographical distribution of the migrant children inflow regions can be derived based on the destinations of the unaccompanied outflow children follow their migrant parents to. Based on the statistics from 2010 Sixth Population Census Data in China, 24.43\% of the Henan migrant workers relocated to Guangdong, 14.19\% relocated to Zhejiang, $11.78 \%$ relocated to Jiangsu, $11.36 \%$ relocated to Beijing, and $9.07 \%$ relocated to Shanghai. Based on those percentages, it can be estimated that among the 830 thousand unaccompanied children who are expected to outflow, 169 thousand are expected to relocate to Guangdong, 118 thousand to Zhejiang, 98 thousand to Jiangsu, 94 thousand to Beijing, and 75 thousand to Shanghai. Summing up all the unaccompanied children expected to migrate to a specific region from different regions, one can derive the total number of inflow migrant children for the province.

As shown in Table 4 below, among the 6.13 million children that have inter-provincial migrant parents, it is estimated that most of them will land in one of the five major migrant inflow regions including Guangdong, Zhejiang, Shanghai, Jiangsu, and Beijing. As expected, based on the results of the simulation analysis, such children total 1.18 million in Guangdong, 0.94 million in Zhejiang, 0.61 million in Shanghai, 1.17 million in Jiangsu, and 0.33 million in Beijing. In summary, 69.13 percent of children who are expected to follow their parents to the developed regions are expected to land in one of the five major migrant inflow cities. 
Table 4. Results of simulation analysis - Inflow

\begin{tabular}{rrrrrrrr}
\hline Outflow & Anflow & Jiangxi & Henan & Hunan & Sichuan & Other & Total \\
\hline Guangdong & 31,954 & 169,965 & 169,461 & 353,665 & 234,025 & 225,846 & $1,184,916$ \\
Shanghai & 186,706 & 44,253 & 75,257 & 17,563 & 56,159 & 233,116 & 613,054 \\
Beijing & 30,858 & 12,825 & 94,220 & 11,693 & 29,256 & 148,829 & 327,681 \\
Zhejiang & 163,956 & 138,965 & 117,732 & 57,613 & 111,567 & 354,033 & 943,866 \\
Jiangsu & 184,722 & 24,054 & 97,748 & 15,603 & 58,507 & 791,942 & $1,172,576$ \\
\hline
\end{tabular}

\subsubsection{Summary}

In summary, the majority of the unaccompanied children in the five major outflow regions will follow their migrant parents to the five major inflow regions. As shown in Figure 4 below, $82.11 \%$ of the migrant children originated from Hunan are expected to follow their parents to Beijing. $66.83 \%$ of the migrant children originated from Henan and $86.65 \%$ of the migrant children originated from Anhui are expected to follow their parents to Guangdong. $74.20 \%$ of the migrant children originated from Jiangxi are expected to follow their parents to Jiangsu. In addition, $61.12 \%$ of the migrant children originated from Sichuan are expected to follow their parents to Shanghai.

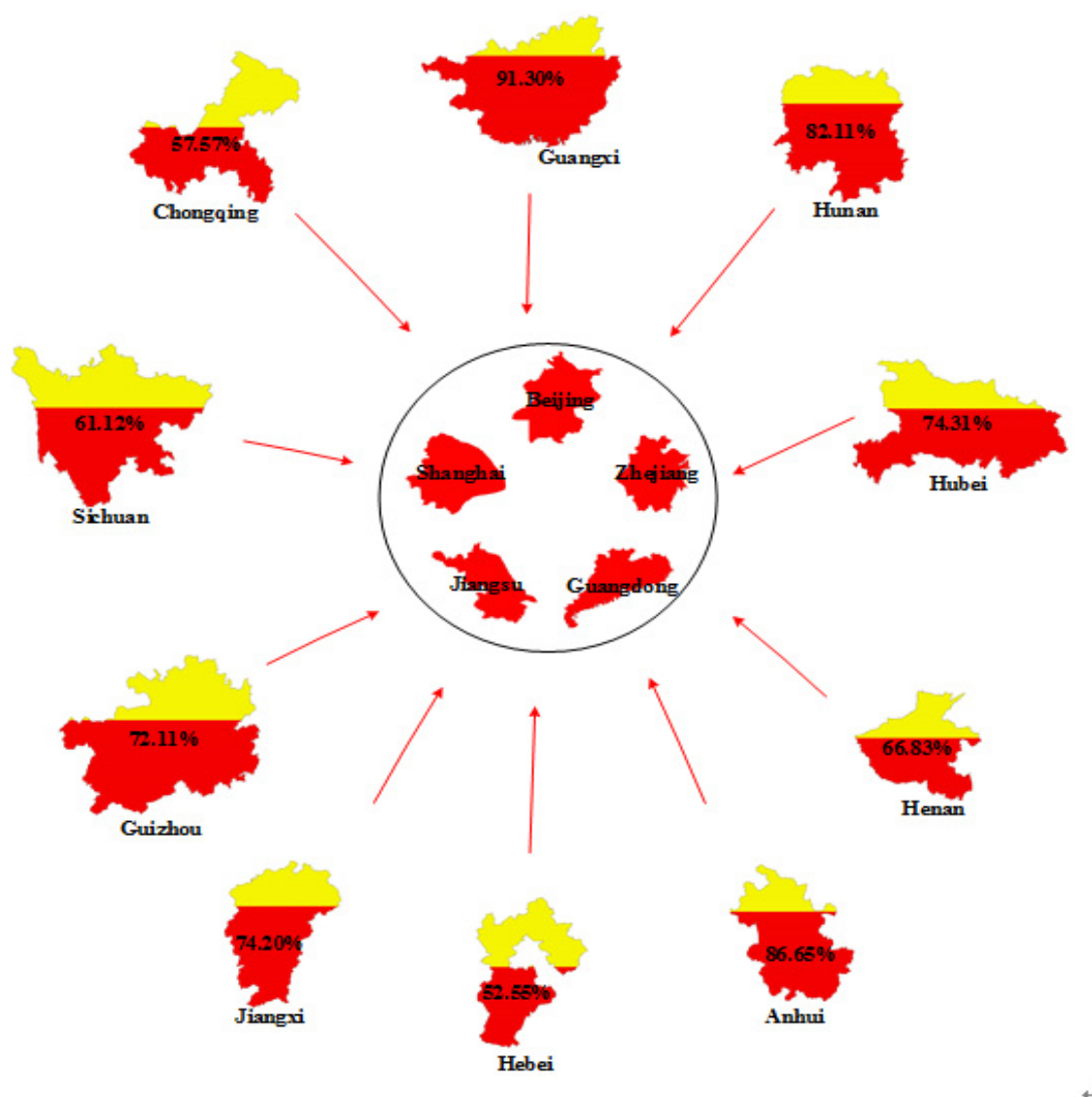

Figure 4. The five major outflow regions and five major inflow regions

\subsection{Capacity Simulation}

Based on the simulated number of children in each region, taking into account the simulated inflow and outflow, educational resources are reallocated. A summary of the adjusted capacity for educational resource after the simulated reallocation of educational resources is presented below in Table 5 . 
Table 5. Simulated educational resource capacities for elementary schools

Human Resource Capacity

- ECCI for Teacher's Workload

\begin{tabular}{cccc}
\hline $\begin{array}{c}\text { Migrant } \\
\text { inflow } \\
\text { Region }\end{array}$ & $\begin{array}{c}\text { ECCI for } \\
\text { Teacher's } \\
\text { Workload }\end{array}$ & $\begin{array}{c}\text { Migrant } \\
\text { outflow } \\
\text { Region }\end{array}$ & $\begin{array}{c}\text { ECCI for } \\
\text { Teacher's } \\
\text { Workload }\end{array}$ \\
\hline Guangdong & 1.30 & Henan & 1.06 \\
Shanghai & 1.52 & Sichuan & 0.90 \\
Beijing & 1.16 & Anhui & 0.92 \\
Zhejiang & 1.33 & Hunan & 1.06 \\
Jiangsu & 1.02 & Jiangxi & 1.16 \\
\hline
\end{tabular}

Material Resource Capacity

- ECCI for School Building Capacity Utilization

\begin{tabular}{cclc}
\hline $\begin{array}{c}\text { Migrant } \\
\text { inflow } \\
\text { Region }\end{array}$ & $\begin{array}{c}\text { ECCI for } \\
\text { School } \\
\text { Building } \\
\text { Capacity } \\
\text { Utilization }\end{array}$ & $\begin{array}{c}\text { Migrant } \\
\text { outflow } \\
\text { Region }\end{array}$ & $\begin{array}{c}\text { ECCI for } \\
\text { School } \\
\text { Building } \\
\text { Capacity } \\
\text { Utilization }\end{array}$ \\
\hline Guangdong & 1.26 & Henan & 1.31 \\
Shanghai & 2.23 & Sichuan & 1.18 \\
Beijing & 1.46 & Anhui & 1.12 \\
Zhejiang & 1.33 & Hunan & 1.07 \\
Jiangsu & 1.18 & Jiangxi & 1.26 \\
\hline
\end{tabular}

Human Resource Capacity

- ECCI for Teacher's Capability

\begin{tabular}{cccc}
\hline $\begin{array}{c}\text { Migrant } \\
\text { inflow } \\
\text { Region }\end{array}$ & $\begin{array}{c}\text { ECCI for } \\
\text { Teacher's } \\
\text { Capability }\end{array}$ & $\begin{array}{c}\text { Migrant } \\
\text { outflow } \\
\text { Region }\end{array}$ & $\begin{array}{c}\text { ECCI for } \\
\text { Teacher's } \\
\text { Capability }\end{array}$ \\
\hline Guangdong & 0.85 & Henan & 0.76 \\
Shanghai & 1.09 & Sichuan & 0.79 \\
Beijing & 1.13 & Anhui & 0.69 \\
Zhejiang & 1.01 & Hunan & 0.71 \\
Jiangsu & 0.97 & Jiangxi & 0.59 \\
\hline
\end{tabular}

Material Resource Capacity

- ECCI for Teaching Facility Capacity Utilization

\begin{tabular}{cccc}
\hline $\begin{array}{c}\text { Migrant } \\
\text { inflow } \\
\text { Region }\end{array}$ & $\begin{array}{c}\text { ECCI for } \\
\text { Teaching } \\
\text { Facility } \\
\text { Capacity } \\
\text { Utilization }\end{array}$ & $\begin{array}{c}\text { Migrant } \\
\text { outflow } \\
\text { Region }\end{array}$ & $\begin{array}{c}\text { ECCI for } \\
\text { Teaching } \\
\text { Facility } \\
\text { Capacity } \\
\text { Utilization }\end{array}$ \\
\hline Guangdong & 1.31 & Henan & 2.81 \\
Shanghai & 0.96 & Sichuan & 1.49 \\
Beijing & 0.58 & Anhui & 1.36 \\
Zhejiang & 0.81 & Hunan & 1.89 \\
Jiangsu & 0.77 & Jiangxi & 2.51 \\
\hline
\end{tabular}

After simulation, educational resources in migrant inflow regions become even tighter while the severe lack of educational resources in migrant outflow regions is effectively alleviated. With respect to the migrant inflow regions, while the double inclusions policy leads to a worse shortage of school building areas and qualified teachers, it effectively improves the utilization of the advanced teaching facilities in migrant inflow regions. Therefore, the flow of demand for educational resources driven by moderate migration can make up for the discrepancy in educational resources, better utilize the teaching facilities, and achieve optimal allocation of educational resources. With respect to the migrant outflow regions, the children's inter-provincial migration raises the education quality, improves the education environment, and alleviates the imbalanced allocation of educational resources in the migrant outflow regions. However, as it compares to the migrant inflow regions, advanced teaching facilities are still insufficient to meet the educational needs after massive migration. In addition, this study has not taken into consideration the scenario when a child migrates within the province of his origin. There exist a large number of migrants migrating within the province in migrant outflow regions, which will also improve the allocation of educational resources in migrant outflow regions.

The difficulty migrant children have in receiving compulsory education cannot be underestimated from both a scale and sustainability perspective. Nevertheless, there are still a large number of migrant children remaining after a part of school-age children in migrant outflow provinces migrate to other regions. Currently, in implementing the National Compulsory Education Project in Poor Areas, government of China makes it a priority to provide financial sponsorship for the poor areas including areas for western ethnic minorities, mountain areas, pastoral areas, and landlocked border areas. It is recommended that government of China extend its help to the major migrant outflow regions and make the associated policy favorable to those regions. Moreover, for the purpose of significantly improving educational services in major migrant outflow regions, it is recommended that government of China come up with a regional make-up plan for the inadequate educational resources in those regions and create more incentives for educational investment (Zhang, 2008). 


\section{Conclusions and Key Implications}

Based on the results of researches and analyses, this paper has the following conclusions: Major migrant inflow regions generally have relative better educational resource capacities. There's still room for further migration and reallocation of educational resources. In contrast, the pressure on educational resource capacity is more severe for migrant outflow regions. The reallocation of educational resources is subject to supply of educational resources Consistent with existing literature. Inadequate educational expenditure leads to imbalanced supply and demand for educational resources. Educational supply is unable to meet the growing social demands for education, such as an improved educational environmental and higher-quality education services. It is also difficult for the supply of financial resources, part of educational resources, to meet the needs of rapid educational development. In particular, insufficient funding for education has become a major factor that prohibits educational development. The flow of demand for educational resources driven by moderate migration is beneficial to evenly allocate educational resources across different regions. Massive migration can accelerate the process of spreading and reallocation of human resources and promote economic development across different regions.

China is now facing serious challenges in the areas of education, the quality of its labor, and in sustaining its economic growth. These challenges can be met by equalizing access to education, reducing restrictions on mobility, and creating effective markets to finance human capital (Heckman, 2012). Massive children's migration has a big impact on the method for allocation of educational resources as well as educational system and policy. It is recommended that central and local governments select a more flexible and more region-specific allocation approach for allocation of educational resources, which adapts to the massive migration and balances educational expenditure across different regions. Existing researches indicate that it is mandatory for education development in China to follow the principles of becoming "developing" and "compensatory" so that national education can be provided to the public on an equal basis, given the severely imbalanced allocation of educational resources across different regions. With respect to the migrant inflow regions, it is encouraged that greater effort be made to accommodate migrant children and promote reasonable migration. It is recommended that public schools reasonably lower barriers to entry and increase admissions. It is also encouraged that educational funds specifically for migrant children be created and admission procedure be simplified. With respect to migrant outflow regions, it is recommended that central government makes favorable policy to those less-developed areas, create specific educational financial sponsorship to lower the local government's educational expenditure.

In addition, priorities should be made for educational expenditures in different regions. More specifically, it is encouraged to raise teaching standards and increase expenditures on advanced teaching facilities in migrant outflow regions. Excessive migration can be effectively reduced once the overall level of education increases in the migrant outflow regions and the pressure can therefore be relieved on capacity for educational resource in migrant inflow regions. It is recommended that building areas be enlarged and number of qualified teachers be increased in migrant inflow regions school. Moreover, it is recommended that adjustments be made to reflect the massive children's migration with respect to allocation of educational resources, and in particular, with respect to allocation of educational expenditure. Feasible and forward-looking educational standards and systems should be created to prohibit inefficient allocation or waste of educational resources. It is recommended that central government make further investments on compulsory education in megacities and super cities where additional capacity for compulsory educational resource is extremely low, and in particular where migrant children concentrate, to alleviate the pressure on education capacity in the cities. Overall, this article is of great significance to further optimize the allocation of educational resources and promote the development of education in the future

\section{References}

Duan, C., \& Yang, K. (2009). Trend in Geographical Distribution for Migrant Inflow. Population Research, 6.

Duan, C., Lv, L., \& Zou, X. (2013). Major Problems Faced by Migrants in China and Associated Solutions. Population Research, 2.

Fang, C. Demographic Transition, Demographic Dividend, and Lewis Turning Point in China. China Economic Journal, (07), 107-119.

Gu, S., \& Pu, Y. (2013). New Social Problem Caused by School-age Migrant Children. Journal of Chongqing University of Education, 26(2).

Heckman, James J., \& Yi, Junjian. (2012). Human Capital, Economic Growth, and Inequality in China. NBER 
Working Paper Series, (5).

Landau, Daniel L. (1997). Government Expenditure, Human Capital Creation and Economic Growth. Journal of Public Budgeting. Accounting and Financial Management, 9(3), Fall, 467-487.

Tooley, J., Bao, Y., Dixon, P., \& Merrifield, J. (2011). School choice and academic performance: Some evidence from developing countries. Journal of School Choice: Research, Theory, and Reform, 5(1), 1-39.

Wang, F., \& Andrew, M. Demographic (2005). Dividend and Prospects for Economic Development in China. United Nations Expert Group Meeting on Social and Economic Implications of Changing Population Age Structures.

$\mathrm{Wu}, \mathrm{P}$. (2010). Research and Evaluation of Educational Resource Capacity. Journal of Shaanxi Institute of Education, 26(3), 1-4.

Wu, Y. (2008). Cultural Capital, the State, and Educational Inequality in China. Sociological Perspectives, 51(1), Spring, 201-227.

Xiang, X. (1998). Education under the Circumstances of Space Displacement of Population. Educational Research, 19(4), 34-38.

Zai, L., \& Yiu Por Chen. (2007). The educational consequence of migration for children in China. Social Science Research, 36, 28-47.

Zhang, J. (2008). Education Spillover, Education Insufficiency, and Education Compensation - External Research on Educational Compensatory Policy for Underprivileged Families and Poor Areas. Educational Research, (7).

\section{Copyrights}

Copyright for this article is retained by the author(s), with first publication rights granted to the journal.

This is an open-access article distributed under the terms and conditions of the Creative Commons Attribution license (http://creativecommons.org/licenses/by/4.0/). 